\title{
Protein Sequencing
}

National Cancer Institute

\section{Source}

National Cancer Institute. Protein Sequencing. NCI Thesaurus. Code C18883.

The process of determining the sequence of amino acids within a protein molecule. 